\title{
Elemental mapping of Portuguese ceramic pieces with a full-field XRF scanner based on a 2D-THCOBRA detector
}

\author{
P. M. S. Carvalho ${ }^{1, \mathrm{a}} \mathbb{D}$, F. Leite ${ }^{2}$, A. L. M. Silva ${ }^{2}$, S. Pessanha ${ }^{1}$, M. L. Carvalho ${ }^{1}$, \\ J. F. C. A. Veloso ${ }^{2}$, J. P. Santos ${ }^{1}$ \\ ${ }^{1}$ Laboratory of Instrumentation, Biomedical Engineering, and Radiation Physics, Department of Physics, \\ NOVA School of Science and Technology, NOVA University Lisbon, Campus Caparica, 2829-516 Monte \\ da Caparica, Portugal \\ 2 I3N - Physics Department, University of Aveiro, Campus de Santiago, 3810-193 Aveiro, Portugal
}

Received: 6 November 2020 / Accepted: 10 April 2021

(C) The Author(s), under exclusive licence to Società Italiana di Fisica and Springer-Verlag GmbH Germany, part of Springer Nature 2021

\begin{abstract}
In this work, we present a novel application of the full-field energy-dispersive Xray fluorescence (EDXRF) imaging system based on a MicroPattern Gaseous Detector (2DTHCOBRA) in the cultural heritage field. The detector has an intrinsic imaging capability with spatial resolution of $400 \mu \mathrm{m}$ FWHM, and is energy sensitive, presenting an energy resolution of approximately $1 \mathrm{keV} \mathrm{FWHM} \mathrm{at} 5.9 \mathrm{keV}$. The full-field XRF scanner based on the 2D-THCOBRA detector allows mapping the distribution of elements in large area samples with high detection efficiency ( $75 \%$ at $5.9 \mathrm{keV})$, being a very promising choice for elemental mapping analysis of large area cultural heritage samples. In this work, we have demonstrated the imaging capabilities of the full-field XRF scanner and used it to assess the restoration of a Portuguese faience piece.
\end{abstract}

\section{Introduction}

Energy-dispersive X-ray fluorescence (EDXRF) analysis techniques are used in several research fields and industrial applications, as they enable non-destructive elemental identification and quantification. Recently, EDXRF imaging (EDXRFI) has become a promising method to obtain positional distribution of specific elements and can be used in several applications, such as food science [1], electronics [2], life sciences [3], and cultural heritage [4].

To obtain the elemental distribution of a sample, specific instrumentation that provides precise positioning and good energy resolution must be used. Micro-X-ray fluorescence (Micro-XRF) imaging spectrometers rely on scanning samples along the $X$ and $Y$ directions, with a micro-X-ray beam irradiating a region of interest (ROI), point by point. The characteristic X-ray photons are detected at each point by means of an energy-dispersive detector (e.g., silicon drift detector). Despite presenting good energy resolution (a few hundred eV) and position resolution (tens of $\mu \mathrm{m}$ range), values considered for laboratory instruments, the acquisition times for large area samples may be quite high, which prompted the devel-

\footnotetext{
a e-mail: pmd.carvalho@ campus.fct.unl.pt (corresponding author)
} 
opment of alternative systems that enable quicker analyses of these kinds of samples. This is particularly important for cultural heritage applications, where the mapping of large area paintings is usually needed, in order to identify pigments, and acquire information regarding changes made to a painting during its production or after restoration [5,6]. Another concern was the need for portable systems for in situ analyses that avoid the constraints of transporting priceless artwork from the dedicated museum environment. Alfeld et al. [5] developed scanning macro-XRF spectrometers, based on X-ray tubes and silicon drift detectors (SDD) mounted on translation stages, that were then tested on different paintings. Scanning speeds of $0.5 \mathrm{~cm}^{2}$ per minute, with a step size of $1 \mathrm{~mm}$, allowing the mapping of samples with areas up to $1500 \mathrm{~cm}^{2}$, were achieved. Romano et al. [7] presented a mobile macro-XRF scanner based on a microfocus X-ray tube and two SDDs simultaneously operated that are mounted on a 3-axis system. The scanner can cover dimensions up to $110 \times 70 \times 20 \mathrm{~cm}^{3}$ with a maximum speed of $100 \mathrm{~mm} / \mathrm{s}$, and it was employed to analyse the chemical composition of a painted wood panel $\left(45 \times 35 \mathrm{~cm}^{2}\right)$.

On the other hand, full-field X-ray fluorescence (FF-XRF) spectrometers eliminate the need for scanning mechanisms by employing broad X-ray beams to irradiate a whole ROI on a sample and simultaneously detecting the emitted radiation with two-dimensional energydispersive detectors, such as charge-coupled devices [8] or Medipix and Timepix detectors [9].

Following the technological improvements of gaseous radiation detectors, new devices enable 2D detection emerged, namely gas electron multiplier (GEM) detectors with twodimensional readout [10], the 2D Micro-Hole and Strip Plate (2D-MHSP) [11], and the 2D Thick COBRA (2D-THCOBRA) [12]. These detectors rely on the ionization of gas atoms, contained in a chamber, by the incident radiation, resulting in the creation of electronion pairs. The generated charge undergoes an amplification process, and the electrons are collected in an anode, thus forming an electrical signal proportional to the energy of the incident radiation [13]. They are characterised by the unlimited dynamic range, high rate capability $\left(>1 \mathrm{MHz} / \mathrm{mm}^{2}\right.$ ), high soft X-ray detection capability $(<1 \mathrm{keV})$, and large detection areas $\left(>10 \times 10 \mathrm{~cm}^{2}\right)$, and have been successfully implemented in different EDXRFI spectrometers [14]. An XRF imaging system for pigment distribution mapping of large area cultural heritage samples was developed by Zielińska et al. [15]. It relies on a triple GEM detector operating in a gas mixture of argon and carbon dioxide flowing through the detector chamber, and a 2D-readout system. Silva et al. [16] successfully employed a 2D-MHSP detector for full field of view imaging of treated and healthy human teeth, having evaluated the distribution of calcium, zinc, and mercury on the studied samples. The MHSP structure is placed on a sealed chamber filled with xenon purified through the use of getters. A large area EDXRFI system based on a 2D-THCOBRA detector was used to analyse a single folio of an illuminated XV-XVI century Book of Tides [17]. This detector guarantees greater charge amplification by using a Thick GEM (THGEM) plate and a THCOBRA plate in a cascade configuration, inside an aluminium vessel through which a neon-methane mixture flows. Distribution maps of calcium, copper, and gold, elements present in the used paints, were obtained. Another EDXRFI system configuration based on a 2D-THCOBRA detector (in a neon-methane atmosphere, with a $10 \times 10 \mathrm{~cm}^{2}$ active area) was used to study the elemental distribution in a contemporary Indian miniature [18]. Different regions were analysed and the results compared with results from acquisitions made with a Micro-XRF spectrometer, the M4 TORNADO (Bruker, Germany). The FF-XRF was shown to be a lowcost alternative to scanning spectrometers, suitable for fast analysis, when only qualitative information regarding the elemental distribution is needed. 
In this work, we use an EDXRFI system based on a 2D-THCOBRA detector with an active area of $10 \times 10 \mathrm{~cm}^{2}$ to analyse a restored Portuguese faience piece from the late XIX-early $\mathrm{XX}$ century. Two contemporary tiles, manufactured according to traditional methods, are also studied to illustrate the capabilities of the presented system.

\section{Experimental set-up}

Decorative glazed ceramic pieces from private collections, namely two contemporary tiles, and a faience piece from the late XIX century-early XX century, were analysed with a FFXRF scanner based on a 2D-THCOBRA detector. For validation of results, two spectrometer systems were used: a benchtop Micro-XRF imaging spectrometer, the M4 TORNADO (Bruker, Germany), and a non-commercial portable XRF spectrometer.

\subsection{Sample description}

A glazed ceramic object can be divided in three main parts: the ceramic support, the glaze, and the surface decoration. The surface decoration, the main feature under study in this paper, can be more or less dispersed within the glassy matrix, depending on the kind of glaze (in terms of chemical composition) and/or the firing temperature used [19].

\subsubsection{Azulejos de Azeitão: contemporary handmade Portuguese tiles}

Azulejos, the Portuguese word for ceramic tiles, have been a staple of Portuguese heritage, ever since their introduction in the country by king D. Manuel I, during the XV century [20]. To this day, tiles are still used as a building material due to their functional capacity (e.g. building insulation), but also as decorative elements, and can be found in many cultural heritage sites or modern infrastructures.

To illustrate the performance and suitability of the FF-XRF scanner for cultural heritage samples, we analysed two contemporary glazed tiles from the company Azulejos de Azeitão, shown in Fig. 1. The company contributes to the preservation of the traditional manufacturing process and manual painting of glazed tiles, using the same process since the XVIII century. The tiles, both flat and relief, feature European, Islamic, Chinese, and Hispano-Moorish designs [21-23].

\subsubsection{Palangana from Ratinho Faience}

Louça Ratinho, everyday glazed tableware, was produced at the Coimbra (Portugal) faience factory from the XIX century to the early XX century. It was named Ratinho in allusion to the rural workers from the Beiras region, who frequently bought the pieces due to its low cost and durability [24]. Most pieces are decorated with motifs such as human figures, animals, flowers, or feathers, painted with sponge and brush [25-27].

In this work, we analyse a palangana, a wide and shallow bowl typically used to serve roasts, with a diameter of $31 \mathrm{~cm}$ and height of $7.5 \mathrm{~cm}$. The presented piece (Fig. 2) was broken years ago and underwent restoration at Laboratório de Conservação e Restauro (LCR) of Escola Superior de Tecnologia de Tomar. However, after some time the piece began to show some discolouration in the restored areas. 


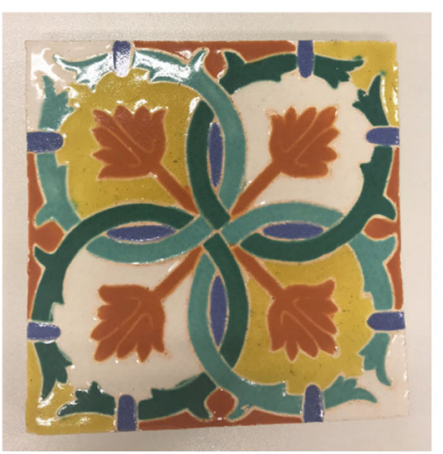

(a) Tile AA01.

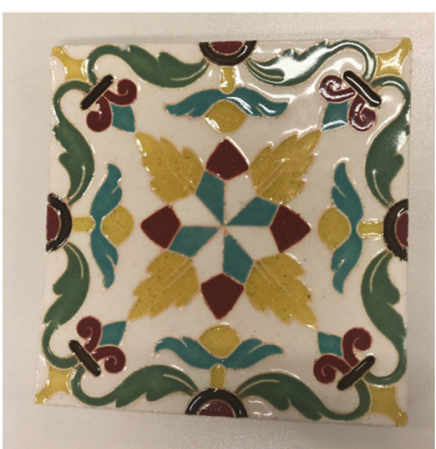

(b) Tile AA02.

Fig. 1 Azulejos de Azeitão

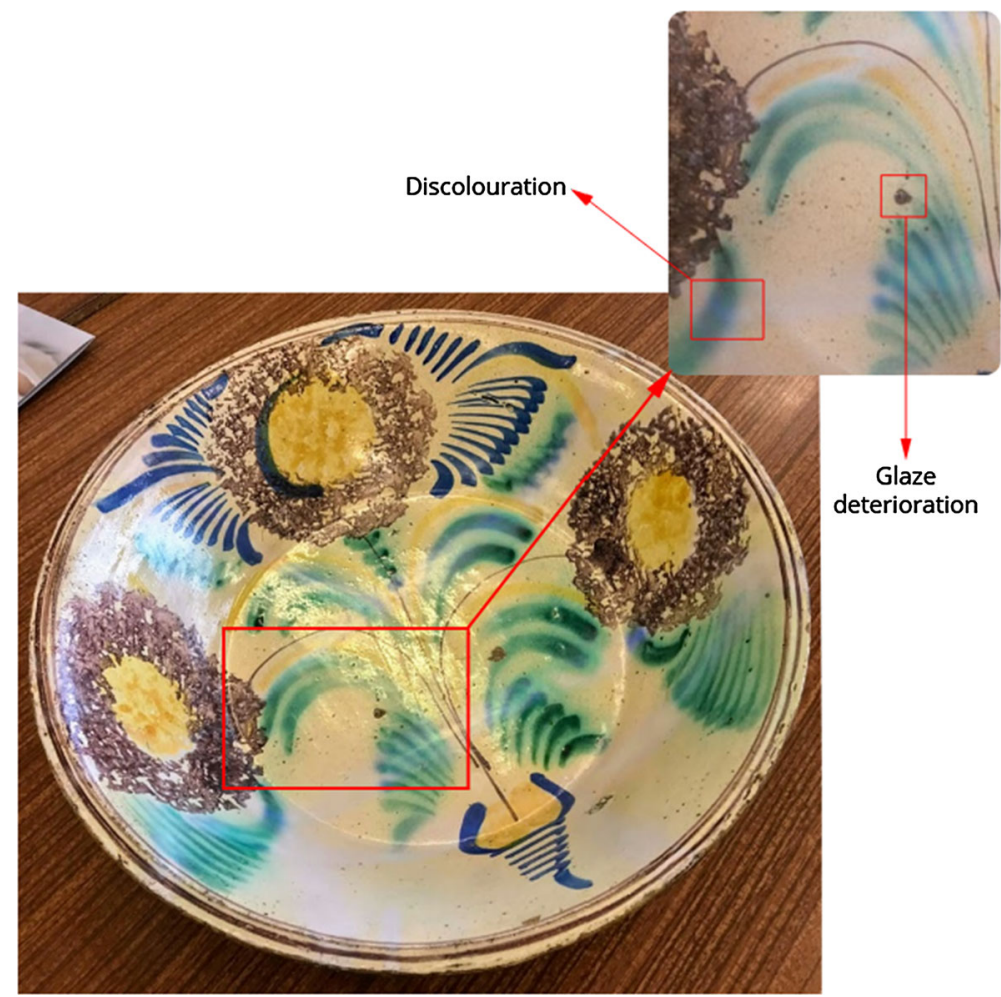

Fig. 2 Palangana from Ratinho Faience, and close-up of a region where it is possible to visualise discolourations due to the restoration, and deterioration of the glaze

\subsection{Full-field XRF scanner based on a 2D-THCOBRA detector}

The FF-XRF system, shown in Fig. 3a, uses an X-ray tube with a molybdenum anode (5000 Apogee series, Oxford Instruments) for sample excitation, a $1 \mathrm{~mm}$ lead pinhole to aid image formation and magnification, and a 2D-THCOBRA detector for detection of the incident 


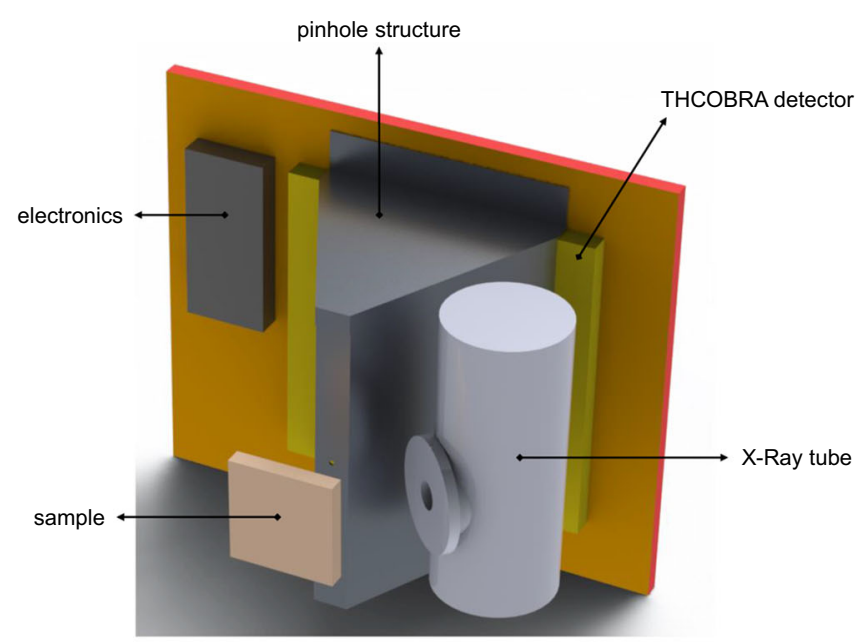

(a) Simplified representation of the FF-XRF spectrometer, highlighting the 2D-THCOBRA detector, the X-Ray tube, the pinhole structure, the sample, and the electronic components.

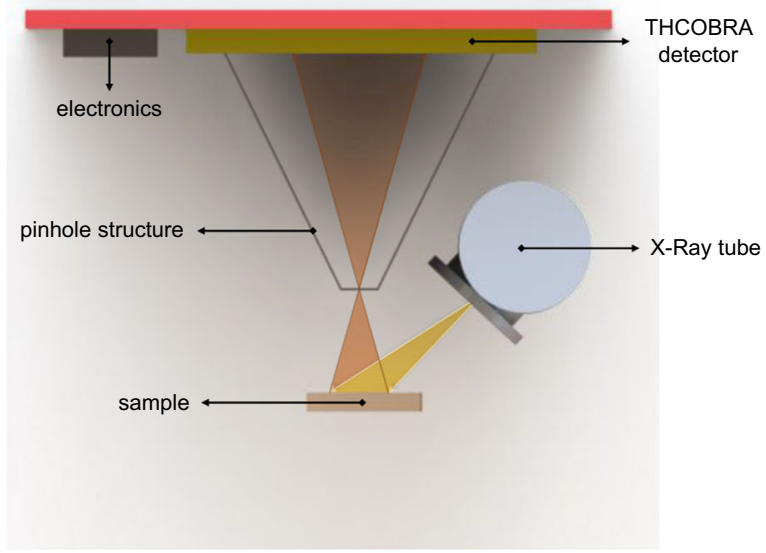

(b) Top view of the FF-XRF spectrometer.

Fig. 3 FF-XRF spectrometer based on a 2D-THCOBRA

photons' energies and 2D mapping. The pinhole, placed $13 \mathrm{~cm}$ away from the detector's window, is coupled to a stainless steel structure coated with a lead foil that absorbs the photons that do not pass through the pinhole. The components are arranged in a planar geometry, and the X-ray tube irradiates the sample with an angle $\approx 45^{\circ}$, as shown in Fig. $3 \mathrm{~b}$. We draw attention to the possibility of positioning the different system components to focus on different ROIs of the samples, which can be helpful to analyse non-flat pieces such as bowls or vases. 
Fig. 4 Simplified schematic operation of the 2D-THCOBRA detector

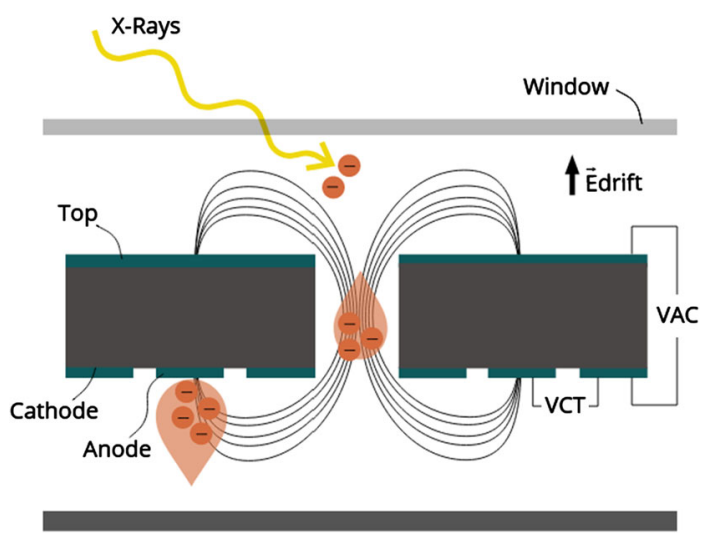

\subsubsection{The 2D-THCOBRA detector}

The 2D-THCOBRA structure consists of $0.4 \mathrm{~mm}$ G10 plate coated with a $50 \mu \mathrm{m}$ copper layer. It has an hexagonal pattern of round holes; on the bottom face, there is a pattern of anode and cathode strips, and on the top face, there are strips orthogonal to the bottom ones [12,28].

The principle of operation of the detector, represented in Fig. 4, is based upon the interaction of incoming X-ray photons with the gas medium, a mixture of $\mathrm{Ne} / \mathrm{CH}_{4}$ flowing continuously through the detector chamber, creating electrons. The electrons are focused on the structure holes due to a weak electric field established in the drift region. Inside the holes, a strong electric field due to the voltage difference between the top and cathode strips $\left(V_{\mathrm{CT}}\right)$ promotes charge multiplication. Again, an electric field due to the voltage difference between the cathode and anode strips $\left(V_{\mathrm{AC}}\right)$ leads to a second charge multiplication near the anode strips, where the bulk of the charge is collected. A thorough description of the detector and its operation can be found on works by Silva et al. [17] and Carramate et al. [29].

Besides determining the energy of each photon that reaches the detector's active area, its position of interaction can also be assessed, enabling 2D mapping. For this purpose, two resistive strips connect the top, and the anode strips; the $\mathrm{X}$ and $\mathrm{Y}$ coordinates of the position of interaction of the incident photon are calculated by the principle of resistive charge division, and its energy, by summing the signal amplitudes at both ends of a single resistive strip $[28,30,31]$.

\subsubsection{Figures of merit}

In this section, the experimental determination of crucial performance parameters of the detector and of the system, namely energy resolution, linearity, and position resolution, is discussed. For these studies, the detector was operated at $V_{\mathrm{AC}}=200 \mathrm{~V}$ and $V_{\mathrm{CT}}=600 \mathrm{~V}$, with a Ne/CH flow of $20 \mathrm{ml}_{\mathrm{n}} / \mathrm{min}$; the $\mathrm{X}$-ray tube was operated at $20 \mathrm{kV}$ and $100 \mu \mathrm{A}$.

\section{Energy resolution and linearity}

The energy resolution $\left(R_{\mathrm{E}}\right)$ can be defined as the detector's response to a mono-energetic radiation source. For a gaseous detector, it is defined by Eq. 1, where the $\omega$ value is the required energy to create one ion pair, $F$ is the Fano factor, characteristic of the used filling 
gas, and $E_{\text {inc. }}$ is the energy of the incident radiation [14].

$$
R_{\mathrm{E}}=2.35 \times \sqrt{\frac{\omega F}{E_{\text {inc }}}}
$$

To determine the energy resolution, the detector was irradiated with $\mathrm{K}$ fluorescence radiation from five different elements (titanium, iron, nickel, copper, and zinc) chosen so that the covered energy range contains the energy of the elements that are expected to be present in the studied samples. The detector was irradiated through a lead collimator with a $4 \mathrm{~mm}$ hole.

Results are shown in Fig. 5. From the graph of Fig. 5a, depicting Eq. 1, we can verify the improvement of the energy resolution with the increase in the incident energy, and determine the energy resolution of the detector as 16\% FWHM@5.90 keV. The detector's linear response, i.e., the peak centroid as a function of the incident energy, is also confirmed (Fig. 5b).

\section{System position resolution}

The position resolution (or spatial resolution) of the system $\left(\lambda_{\mathrm{s}}\right)$ can be defined as the minimum size of an object that can be discriminated and seen in the obtained image [32]. It can be calculated from Eq. 2 [33,34].

$$
\lambda_{\mathrm{s}}=\sqrt{\lambda_{\mathrm{p}}^{2}+\lambda_{\mathrm{i}}^{2}+\lambda_{\Delta \mathrm{x}^{\prime}}^{2}}
$$

The first term of the equation refers to the pinhole contribution, the second, to the intrinsic resolution of the detector, and the third takes into account an uncertainty due to oblique penetration and different X-ray penetration depths. This last contribution is small for higher magnification values and as such is not considered. Equation 2 is rewritten as

$$
\lambda_{\mathrm{s}}=\sqrt{d_{\mathrm{p}}^{2}\left(1+\frac{1}{M}\right)^{2}+\frac{\mathrm{FWHM}_{\mathrm{i}}^{2}}{M^{2}}}
$$

where $d_{\mathrm{p}}$ is the pinhole diameter, and $F W H M_{\mathrm{i}}$ is the intrinsic resolution of the detector. Both contributions are corrected for the magnification $(M)$.

To experimentally determine the position resolution of the FF-XRF scanner, EDXRF images of a $100 \mu \mathrm{m}$ thick hexagonal stainless steel grid, with $2.8 \mathrm{~mm}$ side length and $360 \mu \mathrm{m}$ septa thickness, were acquired, for different magnification values, achieved by varying the distance between the sample and the pinhole. For a pinhole with $1 \mathrm{~mm}$ diameter, a position resolution of approximately $400 \mu \mathrm{m}$ can be achieved, as shown in Fig. 6. An increase in magnification yields better position resolution values that will tend towards a value approximate to the pinhole's diameter. In practice, the position resolution value is smaller than expected, due to the non-negligible thickness of the pinhole that causes the system to "see" a smaller effective diameter. Furthermore, the use of smaller diameter pinholes can lead to an improvement of the position resolution, at the expense of the system's sensitivity (i.e., fewer photons will reach the detector's active area) and of the acquisition time.

\subsection{Portable XRF and Micro-XRF}

For the validation of the results obtained with the FF-XRF scanner for the analysis of the glazed ceramic, two different EDXRF spectrometer systems were used. To map the elemental distribution of the ceramic tiles, a Micro-XRF spectrometer, the M4 TORNADO (Bruker, 


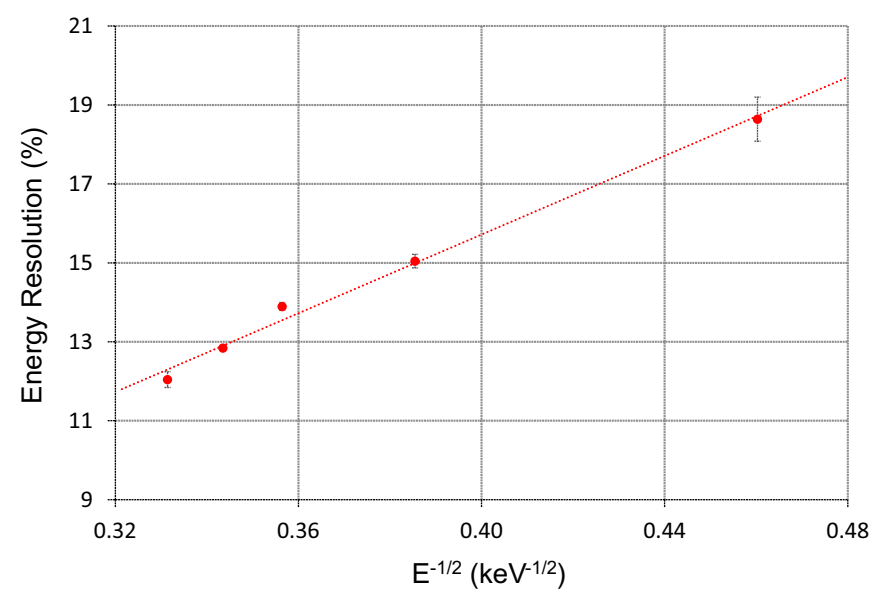

(a) Energy resolution as a function of the inverse of the square root of the incident energy. Error bars represent the uncertainty of the energy resolution values, calculated via error propagation.

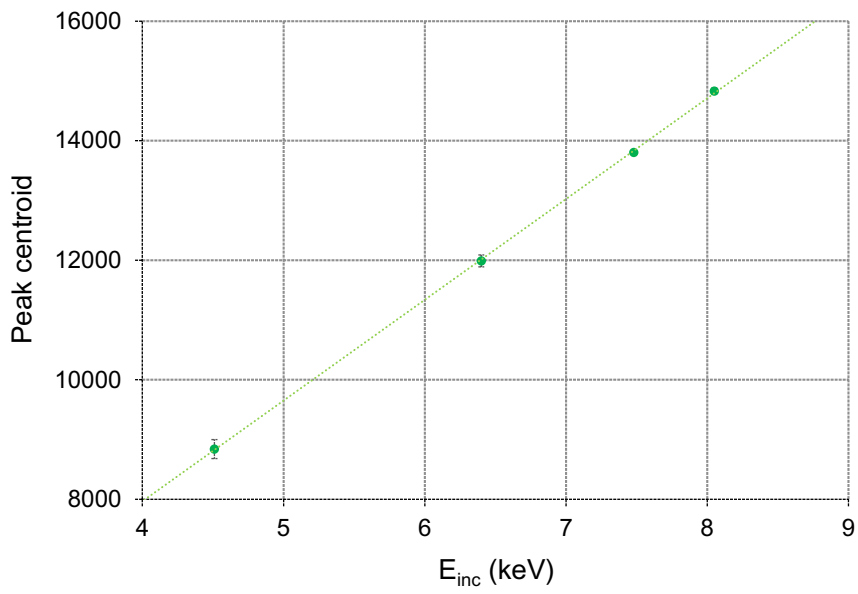

(b) Linearity: Peak centroid as a function of the incident energy. Error bars represent the uncertainty of the peak centroid values, calculated via error propagation.

Fig. 5 Energy resolution and linear response of the 2D-THCOBRA detector

Germany), was used. Because the shape and dimensions of the faience piece inhibit the use of the M4 TORNADO, a portable compact XRF system was used to assess its elemental composition.

The XRF portable set-up consists of an X-ray generator, the Mini-X with a rhodium target, (50 kV, $200 \mu \mathrm{A}$, max.) from Amptek Inc., (Bedford, USA), and a X-123 Silicon Drift Detector (SDD) $\left(25 \mathrm{~mm}^{2}\right.$ detection area, $500 \mu \mathrm{m}$ thickness, and a $12.5 \mu \mathrm{m}$ Be window) with an energy resolution of $140 \mathrm{eV} \mathrm{FWHM} \mathrm{for} \mathrm{the} \mathrm{K} \mathrm{line} \mathrm{of} \mathrm{manganese} \mathrm{(5.90} \mathrm{keV),} \mathrm{also} \mathrm{from} \mathrm{Amptek} \mathrm{Inc.,}$ (Bedford, USA). The X-ray tube was operated at $40 \mathrm{kV}$ and $40 \mu \mathrm{A}$, and the acquisition time was of $60 \mathrm{~s}$. The portable system is assembled using a polymethylmethacrylate plate mounted 

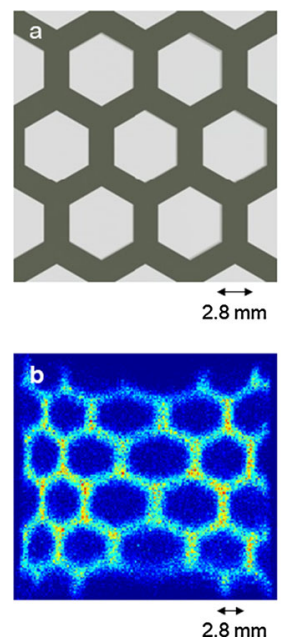

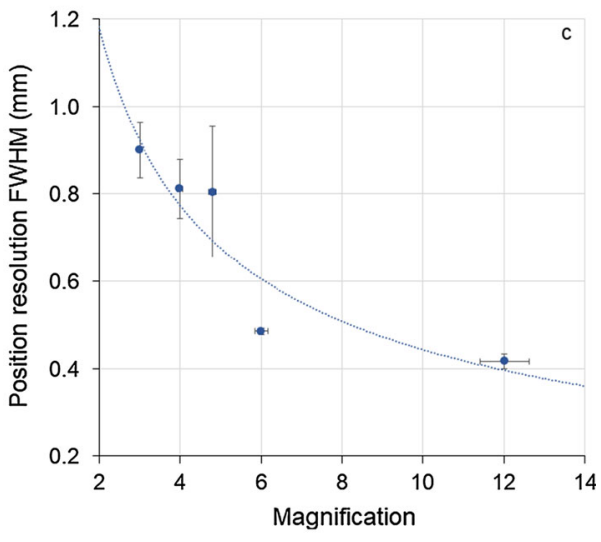

Fig. 6 Position resolution of the FF-XRF scanner based on the 2D-THCOBRA detector. a Representation of the stainless steel grid. b EDXRF image of the grid, obtained with a $1 \mathrm{~mm}$ pinhole, and $M=4$. $\mathbf{c}$ Position resolution FWHM (mm) as a function of magnification. Error bars represent the uncertainty of the position resolution and of the magnification values, calculated via error propagation

on a tripod. Different configuration geometries are allowed between the X-ray tube and the detector; in this work, a $90^{\circ}$ geometry was used.

The M4 TORNADO Micro-XRF spectrometer allows the analysis of small and large samples (solids, particles, and liquids) with little preparation. It uses poly-capillary X-ray optics with spot sizes under $25 \mu \mathrm{m}$ for Mo-K radiation. The excitation of samples is achieved by using an X-ray tube with a Rh target (operated at $50 \mathrm{kV}, 300 \mu \mathrm{A}$ ). The spectrometer uses a SDD with a sensitive area of $30 \mathrm{~mm}^{2}$, and energy resolution $<145 \mathrm{eV} @ 5.9 \mathrm{keV}$. In order to obtain the elemental distribution of the ceramic tiles, area acquisitions were performed: mappings were made on different regions, using a step size of $35 \mu \mathrm{m}$ and time per step of $1 \mathrm{~ms}$.

\section{Results and discussion}

\subsection{Mapping of the ceramic tiles}

Results from the analysis of the ceramic tiles with the FF-XRF scanner are presented in Figs. 7 and 8 . For the analysis of both tiles, the detector was set at $V_{\mathrm{AC}}=190 \mathrm{~V}$ and $V_{\mathrm{CT}}=590 \mathrm{~V}$. The image from the ceramic tile AA01 was acquired with a magnification factor of $\times 2.6$, and the acquisition was performed with the $\mathrm{X}$-ray tube operating at $40 \mathrm{kV}$ and $40 \mu \mathrm{A}$, during $75 \mathrm{~min}$; in the case of ceramic tile AA02, the magnification factor was of $\times 1.3$, and the $\mathrm{X}$-ray tube was operated at $35 \mathrm{kV}$ and $40 \mu \mathrm{A}$, during $59 \mathrm{~min}$.

In both spectra, it is possible to identify the $\mathrm{L} \alpha$ fluorescence lines of $\mathrm{Pb}$ from the glaze of the tiles. If the energy range of the peak is selected, an image of its distribution is obtained. In both maps (Figs. 7c and 8c), we can see that the distribution of $\mathrm{Pb}$ is uniform, as the glaze coats the entire surface of the tiles. In the fluorescence spectra of tile AA01, the energy range of copper was selected. The obtained map (Fig. 7c) shows the detail of the irradiated ROI, 

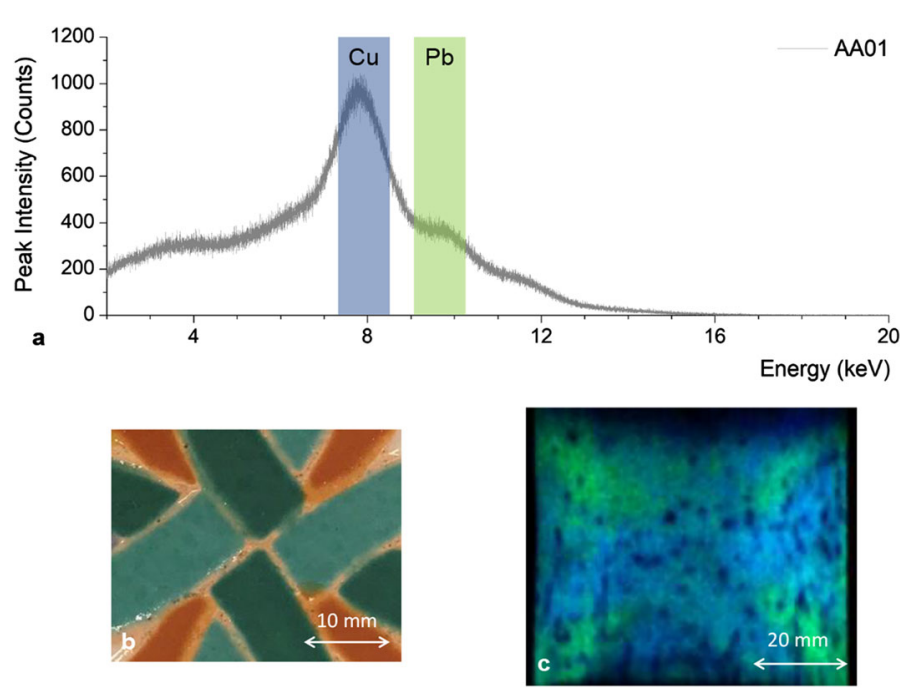

Fig. 7 Results from the analysis of tile AA01 with the FF-XRF scanner. a Intensity as a function of incident energy, where the energy range of copper is selected, as well as the energy range of lead. b Analysed ROI. c $\mathrm{Cu}$ and $\mathrm{Pb}$ map

the ribbons in light and dark green tones, whose pigments contain copper. In the fluorescence spectra of tile AA02, the energy ranges of copper and zinc were selected. Because the K fluorescence energies of these elements are close, there is an overlap of the characteristic peaks. The obtained map (Fig. 8c) shows the details of the irradiated ROI: dark green leaves and the teal rhombus, containing $\mathrm{Cu}$ and $\mathrm{Zn}$.

In both elemental distribution maps, dark regions are also identified. These are due to electric discharges of the detector. It must also be noted that the distribution maps are obtained after the application of an amplitude correction method to each EDXRF spectrum. This method compensates the non-uniform amplitude response of the detector, that is due to small defects over the structure [31].

Analyses of the ceramic tiles with the M4 TORNADO spectrometer confirm the presence of $\mathrm{Pb}$ throughout their surface. Moreover, the distribution maps of $\mathrm{Cu}$ in tile AA01 (Fig. 9a) and of $\mathrm{Cu}$ and $\mathrm{Zn}$ in tile AA02 (Fig. 9b) were also obtained, confirming the results of the FF-XRF scanner. Mappings of tiles AA01 and AA02 were acquired according to the set-up and parameters described in Sect. 2.3: with areas of approximately $3 \times 2 \mathrm{~cm}^{2}$ and $4 \times 4 \mathrm{~cm}^{2}$, respectively, overall acquisition times were of $30 \mathrm{~min}$ and $44 \mathrm{~min}$. For larger areas, measure times increase greatly, and memory constraints arise. The presented full-field scanner can overcome these limitations-using appropriate pinhole optics and filling gases, larger areas can be mapped with reduced measure times and no memory constraints.

These maps also highlight the contrast between the performance of the FF-XRF scanner and of the Micro-XRF spectrometer. For the $\mathrm{Cu}$ and $\mathrm{Zn} \mathrm{K}$-alpha energies, the presented scanner has energy resolution values of $1.1 \mathrm{keV}$ FWHM and $1.0 \mathrm{keV}$ FWHM, respectively, whilst the M4 TORNADO presents values of a few hundred keV. Also, with the FF-XRF system, position resolution values between $0.4 \mathrm{~mm}$ and $1 \mathrm{~mm}$ can be achieved; the M4 TORNADO allows mapping with a lateral resolution of $25 \mu \mathrm{m}$. It should be noted that both energy and position resolution of the full-field scanner are limited by the physical principle of charge production on the filling gas, as explained in detail in [35]. Furthermore, the M4 

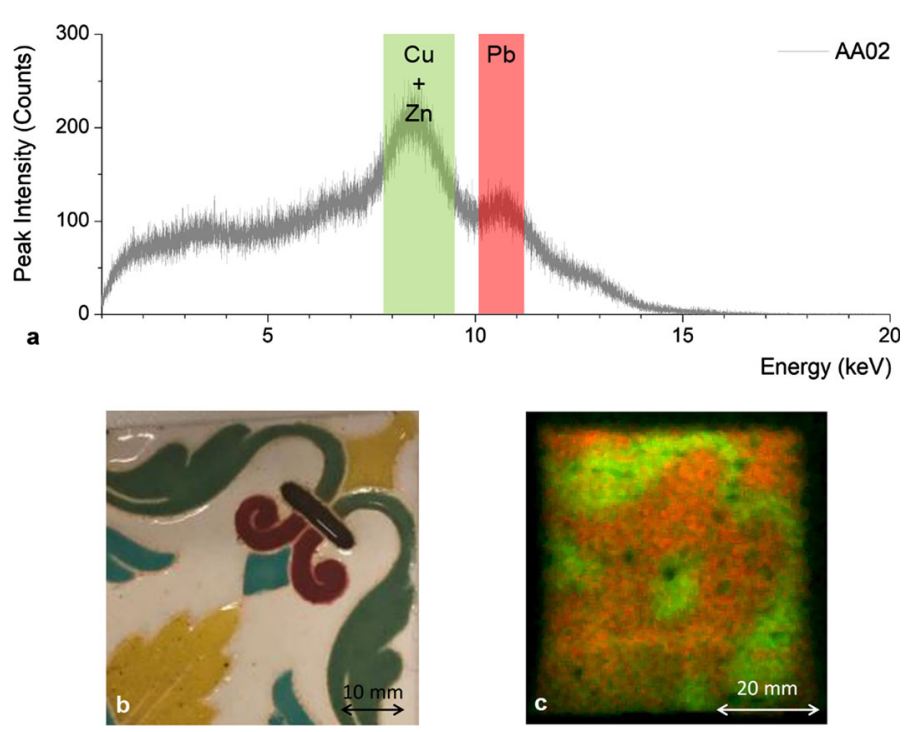

Fig. 8 Results from the analysis of tile AA02 with the FF-XRF scanner. a Intensity as a function of incident energy, where the energy ranges of copper and zinc are selected, as well as the energy range of lead. b Analysed ROI. c $\mathrm{Cu}, \mathrm{Zn}$, and $\mathrm{Pb}$ map

TORNADO allows for higher sensitivity and better detection limits, because of its operation principle: a micro-X-ray beam irradiates a ROI point by point, being the emitted X-ray photons detected at each point. With the full-field system, an entire ROI is irradiated at once, and the emitted radiation is simultaneously detected, decreasing sensitivity and detection limits. A more exhaustive discussion comparing the performance of both systems, including sensitivity, image quality, and limits of detection, is presented by Silva et al. [18].

\subsection{Analysis of the palangana's restoration}

Results from the analysis of the faience piece with the FF-XRF scanner are presented in Fig. 10. For this analysis, the detector was set at $V_{\mathrm{AC}}=190 \mathrm{~V}$ and $V_{\mathrm{CT}}=590 \mathrm{~V}$, and the $\mathrm{X}$-ray tube was operated at $40 \mathrm{kV}$ and $300 \mu \mathrm{A}$. The sample was placed at $7.5 \mathrm{~cm}$ from the pinhole structure, yielding a magnification of 1.73. Acquisition time was of $100 \mathrm{~min}$.

In the obtained spectrum (Fig. 10a), fluorescence peaks of titanium, iron, copper, and lead are identified. Selecting the energy ranges of titanium and lead, a map of the distribution of these elements is obtained (Fig. 10c and d). The presence of titanium along the restored cracks is visible, indicating that this element comes from the material used for the restoration of the piece, and is not present in its core material. Areas with lower concentrations of lead, from the deterioration of the glazed with time, are also identified.

We can also infer the higher concentration of titanium in the restored areas through the analysis of the intensity profile, obtained when a section of the individual distribution map is selected (Fig. 11a). A high intensity peak is identified in the aforementioned profile. Doing the same for the $\mathrm{Pb}$ distribution maps (Fig. 11b) highlights the deterioration of the lead glaze, verified by the sharp decrease in intensity.

The comparison of the spectra acquired with the portable XRF set-up for the faience piece, shown in Fig. 12, allows us to verify the elemental composition of the original piece 


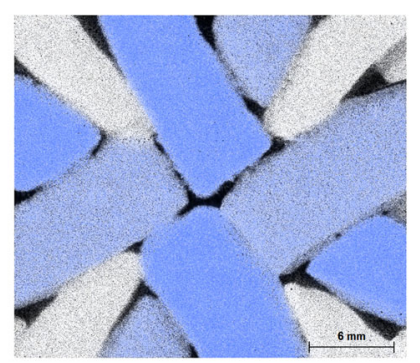

(a) $\mathrm{Cu}$ (blue) and $\mathrm{Pb}$ (white) distribution map in the analysed ROI of tile AA01.

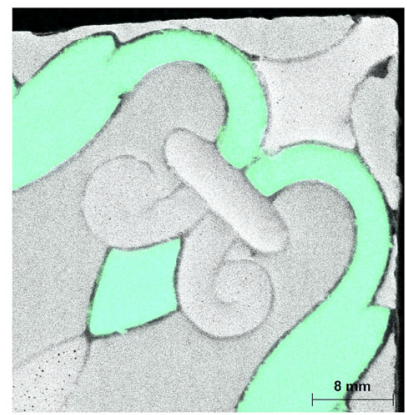

(b) $\mathrm{Cu}, \mathrm{Zn}$ (green) and $\mathrm{Pb}$ (white) distribution map in the analysed ROI of tile AA02.

Fig. 9 Area mappings obtained with the M4 TORNADO spectrometer

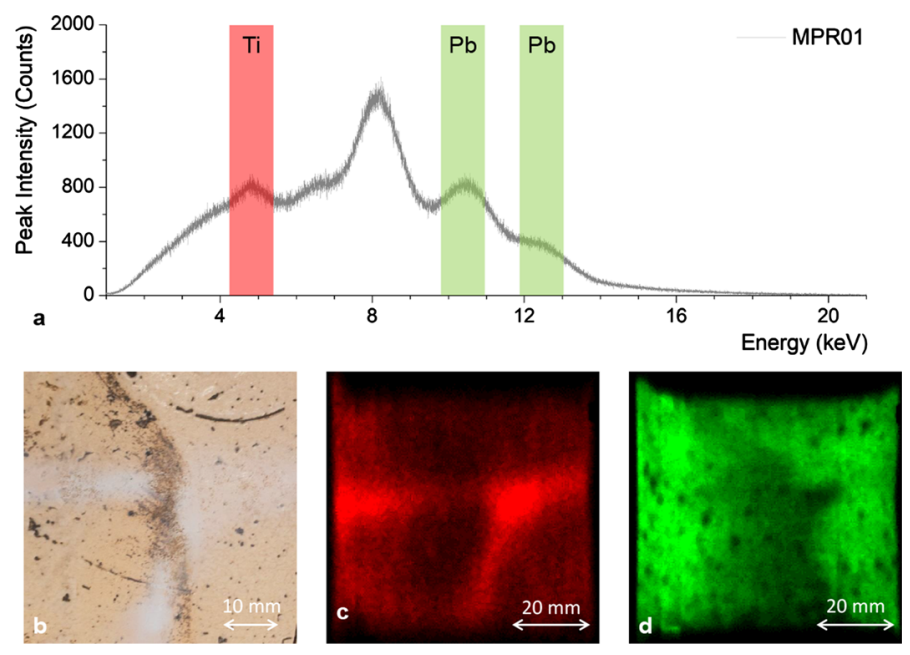

Fig. 10 Analysis of the faience piece with the FF-XRF scanner. a Intensity as a function of incident energy, where the energy ranges of $\mathrm{Ti}$ (red) and $\mathrm{Pb}$ (green) are selected. b Analysed ROI-close-up of the bottom of the piece, where it is possible to identify restored cracks. $\mathbf{c}$ and $\mathbf{d}$ Mapping of the $\mathrm{Ti}$ (red) and $\mathrm{Pb}$ (green) distributions in the analysed ROI 


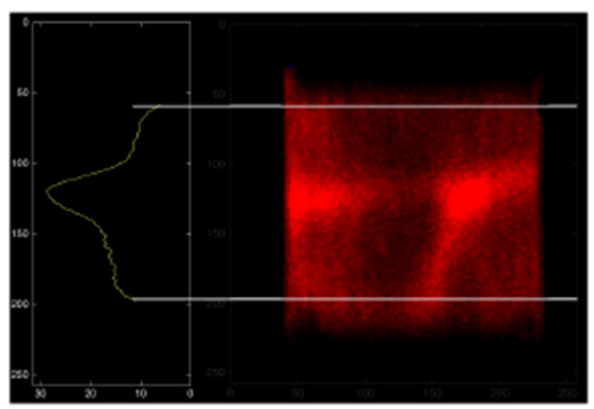

(a) Ti intensity profile

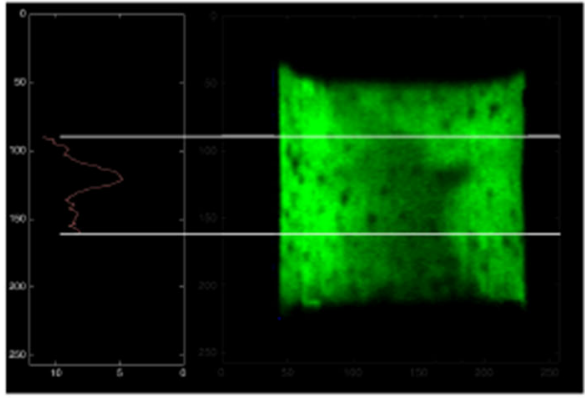

(b) $\mathrm{Pb}$ intensity profile

Fig. 11 Intensity profiles of selected regions in the individual elemental distribution images

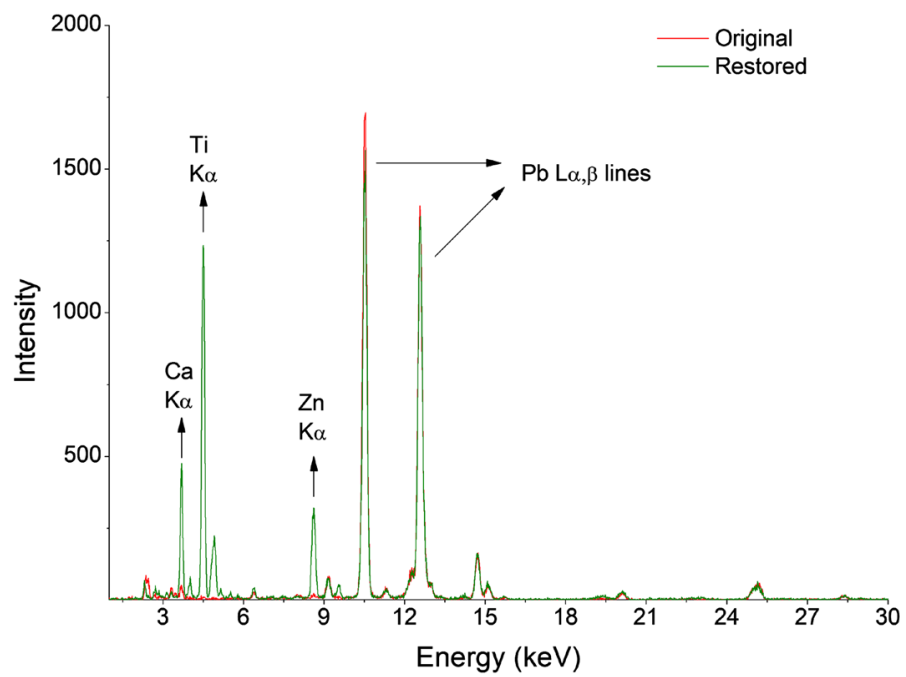

Fig. 12 Comparison of spectra from two different ROIs of the palangana, obtained with the portable XRF. The green spectrum corresponds to a restored area of the piece, and the red one to an untouched area. Characteristic fluorescence peaks of the different $\mathrm{Pb}$ transitions can be identified, as well as peaks from other elements, such as $\mathrm{Ca}, \mathrm{Ti}$, and $\mathrm{Zn}$

and of its restored areas. As expected from the analysis with the FF-XRF spectrometer, fluorescence peaks of titanium are identified only in the restored areas (corresponding to the green spectrum). Furthermore, it is also possible to identify the presence of calcium and zinc in the restored areas of the faience piece.

\section{Conclusions}

In this work, we have presented an EDXRF imaging spectrometer based on a 2D-THCOBRA detector that allows the determination of the energy of incident photons and of their positions of interaction, providing 2D elemental maps of large area samples. The presented system achieves an energy resolution value of $16 \%$ for $5.90 \mathrm{keV}$ X-ray photons, and position reso- 
lution of $400 \mu \mathrm{m}$ using a $1 \mathrm{~mm}$ diameter pinhole. We have shown the system's suitability for cultural heritage applications through the analysis of Portuguese ceramic pieces.

Regarding the analysis of the glazed ceramic tiles, we were able to map the distribution of lead, present in the glaze, and the distribution of copper, and zinc present in the pigments used for decoration, obtaining images where some of the details of the tiles can be discriminated. With respect to the analysis of the faience piece, we assessed its restoration, revealing the presence of titanium in the restored areas that may have led to discolourations on the piece. We have also assessed deterioration of the glaze, by analysing the lead distribution maps. These results indicate the suitability of the full-field XRF scanner to identify chemical elements in cultural heritage objects, and to evaluate differences of the compositions throughout samples, which is, for example, a major issue for forgery proof.

The advantages of this system are clear: it presents a reduced cost (under tens of $k €$ ) compared to the traditionally used systems relying on solid-state detectors, and fast acquisitions of large area samples are possible. The system is also advantageous to analyse odd shaped samples, as one can freely position the different components of the system to irradiate different ROIs. However, there is room for improvement of the system's performance by changing the used filling gas/gas mixture to increase detection efficiency, energy resolution, and position resolution, and by employing different optics such as multi-hole collimators that better the sensitivity of the system, without increasing the acquisition time.

Acknowledgements This work was partially supported by project PTDC/FIS-AQM/32536/2017 through FEDER and FCT (Portugal) programs, by Projects UIDB/50025/2020 and UIDP/50025/2020 financed by national funds through the FCT/MEC, and by the research centre Grant UID/FIS/04559/2020 to LIBPhys-UNL from the FCT/MCTES/PIDDAC (Portugal). P. M. S. Carvalho acknowledges the support of FCT (Portugal) under Contract No. PD/BD/128324/2017.

\section{References}

1. A.V. de J. Mangueze, M.F.G. Pessoa, M.J. Silva, A. Ndayiragije, H.E. Magaia, V.S.I. Cossa, F.H. Reboredo, M.L. Carvalho, J.P. Santos, M. Guerra, A.I. Ribeiro-Barros, F.C. Lidon, J.C. Ramalho, Simultaneous zinc and selenium biofortification in rice. Accumulation, localization and implications on the overall mineral content of the flour. J. Cereal Sci. 82, 34-41 (2018). https://doi.org/10.1016/j.jcs.2018.05.005

2. S. Komatani, T. Aoyama, T. Nakazawa, K. Tsuji, Comparison of SEM-EDS, Micro-XRF and confocal Micro-XRF for electric device analysis. e-J. Surf. Sci. Nanotechnol. 11, 133-137 (2013). https://doi.org/ 10.1380/ejssnt.2013.133

3. R.G. Figueroa, E. Lozano, F. Belmar, D. Alcaman, A. von Bohlen, C.A.B. Oliveira, A.L.M. Silva, J.F.C.A. Veloso, Characteristics of a robust and portable large area X-ray fluorescence imaging system. X-Ray Spectrom. 43(2), 126-130 (2014). https://doi.org/10.1002/xrs.2527

4. M. Manso, S. Pessanha, M. Guerra, J.L. Figueirinhas, J.P. Santos, M.L. Carvalho, Unveiling the third secret of Fátima: $\mu$-XRF quantitative characterization and 2D elemental mapping. Spectrochim. Acta B 130, 35-38 (2017). https://doi.org/10.1016/j.sab.2017.02.006

5. M. Alfeld, K. Janssens, J. Dik, W. de Nolf, G. van der Snickt, Optimization of mobile scanning MacroXRF systems for the in situ investigation of historical paintings. J. Anal. At. Spectrom. 26, 899-909 (2011). https://doi.org/10.1039/C0JA00257G

6. M. Alfeld, J.V. Pedroso, M. van Eikema Hommes, G. Van der Snickt, G. Tauber, J. Blaas, M. Haschke, K. Erler, J. Dik, K. Janssens, A mobile instrument for in situ scanning Macro-XRF investigation of historical paintings. J. Anal. At. Spectrom. 28, 760-767 (2013). https://doi.org/10.1039/C3JA30341A

7. F.P. Romano, C. Caliri, P. Nicotra, S. Di Martino, L. Pappalardo, F. Rizzo, H.C. Santos, Real-time elemental imaging of large dimension paintings with a novel mobile macro X-ray fluorescence (MA-XRF) scanning technique. J. Anal. At. Spectrom. 32, 773-781 (2017). https://doi.org/10.1039/C6JA00439C

8. B. De Samber, O. Scharf, G. Buzanich, J. Garrevoet, P. Tack, M. Radtke, H. Riesemeier, U. Reinholz, R. Evens, K. De Schamphelaere, G. Falkenberg, C. Janssen, L. Vincze, Three-dimensional X-ray fluorescence imaging modes for biological specimens using a full-field energy dispersive CCD camera. J. Anal. At. Spectrom. 34, 2083-2093 (2019). https://doi.org/10.1039/C9JA00198K 
9. J. Dudak, High-resolution x-ray imaging applications of hybrid-pixel photon counting detectors timepix. Radiat. Meas. 137, 106409 (2020). https://doi.org/10.1016/j.radmeas.2020.106409

10. A. Bressan, R.R. De Oliveira, A. Gandi, J.-C. Labbé, L. Ropelewski, F. Sauli, D. Mörmann, T. Müller, H.J. Simonis, Two-dimensional readout of gem detectors. Nucl. Instrum. Methods Phys. Res. A 425(1), 254-261 (1999). https://doi.org/10.1016/S0168-9002(98)01405-3

11. J.M. Maia, J.F.C.A. Veloso, J.M.F. dos Santos, A. Breskin, R. Chechik, D. Mörmann, Advances in the micro-hole \& strip plate gaseous detector. Nucl. Instrum. Methods Phys. Res. B 504(1-3), 364-368 (2003). https://doi.org/10.1016/S0168-9002(03)00772-1. ISSN 01689002

12. F.D. Amaro, C. Santos, J.F.C.A. Veloso, A. Breskin, R. Chechik, J.M.F. Dos Santos, The thick-COBRA: a new gaseous electron multiplier for radiation detectors. J. Instrum. (2010). https://doi.org/10.1088/17480221/5/10/P10002

13. F. Sauli, Gaseous Radiation Detectors-Fundamentals and Applications (Cambridge University Press, Cambridge, 2014). ISBN 9781107043015

14. J.F.C.A. Veloso, A.L.M. Silva, Gaseous detectors for energy dispersive x-ray fluorescence analysis. Nucl. Instrum. Methods Phys. Res. B 878, 24-39 (2018). https://doi.org/10.1016/j.nima.2017.09.011. ISSN 0168-9002

15. A. Zielińska, W. Dą̧browski, T. Fiutowski, B. Mindur, P. Wiącek, P. Wróbel, X-ray fluorescence imaging system for fast mapping of pigment distributions in cultural heritage paintings. J. Instrum. (2013). https:// doi.org/10.1088/1748-0221/8/10/P10011

16. A.L.M. Silva, R. Figueroa, A. Jaramillo, M.L. Carvalho, J.F.C.A. Veloso, Performance of a gaseous detector based energy dispersive X-ray fluorescence imaging system: analysis of human teeth treated with dental amalgam. Spectrochim. Acta B 86, 115-122 (2013a). https://doi.org/10.1016/j.sab.2013.03. 005

17. A.L.M. Silva, M.L. Carvalho, K. Janssens, J.F.C.A. Veloso, A large area full-field EDXRF imaging system based on a THCOBRA gaseous detector. J. Anal. At. Spectrom. 30(2), 343-352 (2015). https://doi.org/ 10.1039/C4JA00301B

18. A.L.M. Silva, S. Cirino, M.L. Carvalho, M. Manso, S. Pessanha, C.D.R. Azevedo, L.F.N.D. Carramate, J.P. Santos, M. Guerra, J.F.C.A. Veloso, Elemental mapping in a contemporary miniature by full-field $\mathrm{X}$-ray fluorescence imaging with gaseous detector versus scanning X-ray fluorescence imaging with polycapillary optics. Spectrochim. Acta B 129, 1-7 (2017). https://doi.org/10.1016/j.sab.2016.12.006

19. A. Guilherme, J. Coroado, J.M.F. dos Santos, L. Lühl, T. Wolff, B. Kanngießer, M.L. Carvalho, X-ray fluorescence (conventional and 3D) and scanning electron microscopy for the investigation of Portuguese polychrome glazed ceramics: advances in the knowledge of the manufacturing techniques. Spectrochim. Acta B 66(5), 297-307 (2011). https://doi.org/10.1016/j.sab.2011.02.007. Thematic Issue 11th Rio Symposium on Atomic Spectrometry

20. R. Mitchell, Portuguese art: Portuguese Azulejos, in Fine Arts Eur. last 10 Centuries., ed. by E. Delle Donne. (Michelangelo Project/Pixel, 2017), pp. 341-360

21. A. de Azeitão, a. https://www.azulejosdeazeitao.com/

22. A. de Azeitão: Um símbolo da cultura portuguesa, b. https://www.aquelesqueviajam.com/azulejos-deazeitao-um-simbolo-da-cultura-portuguesa/

23. A. de Azeitão, c. https://www.allaboutportugal.pt/pt/setubal/saberes-e-sabores/azulejos-de-azeitao

24. F. Antunes Formigo, Estudo decorativo, morfológico e tecnológico da faiança de Coimbra. Master dissertation, Instituto Politécnico de Tomar, (2015). https://comum.rcaap.pt/handle/10400.26/8280

25. Peça do mês - janeiro (2014), a. https://blogs.ua.pt/galeria/?p=1318

26. Louça Portuguesa - Faiança Ratinha, b. http://museuvirtual.activa-manteigas.com/index.php/places/ colecao-privada/louca-portuguesa-faianca-ratinha/

27. Os Ratinhos - fainç popular de Coimbra, c. http://azulporcelana.blogspot.com/2010/05/os-ratinhosfaianca-popular-de-coimbra.html

28. A.L.M. Silva, C.D.R. Azevedo, L.F.N.D. Carramate, T. Lopes, I.F. Castro, R. De Oliveira, J.F.C.A. Veloso, X-ray imaging detector based on a position sensitive THCOBRA with resistive line. J. Instrum. (2013b). https://doi.org/10.1088/1748-0221/8/05/P05016

29. L.F.N.D. Carramate, A.L.M. Silva, C.D.R. Azevedo, D.S. Covita, J.F.C.A. Veloso, THCOBRA X-ray imaging detector operating in Ne/CH4. J. Instrum. 10(1), 10-19 (2015). https://doi.org/10.1088/17480221/10/01/P01003

30. H.N.H.N. Da Luz, C.A.B. Oliveira, C.D.R. Azevedo, J.A. Mir, R. De Oliveira, J.M.F. Dos Santos, J.F.C.A. Veloso, Single photon counting X-ray imaging system using a micro hole and strip plate. IEEE Trans. Nucl. Sci. 55(4), 2341-2345 (2008). https://doi.org/10.1109/TNS.2008.2001423

31. J.F.C.A. Veloso, A.L.M. Silva, C.A.B. Oliveira, A.L. Gouvêa, C.D.R. Azevedo, L. Carramate, H. Natal da Luz, J.M.F. dos Santos, Energy resolved X-ray fluorescence imaging based on a micropattern gas detector. Spectrochim. Acta B 65(3), 241-247 (2010). https://doi.org/10.1016/j.sab.2010.03.006 
32. Jerrold T. Bushberg, J. Anthony Seibert, Edwin M. Leidholdt Jr., John M. Boone. The Essential Physics of Medical Imaging. Lippincott Williams \& Wilkins, 3 edition (2002). ISBN 978-0-7817-8057-5

33. R. Accorsi, Analytic determination of the resolution-equivalent effective diameter of a pinhole collimator. IEEE Trans Med Imaging 23(6), 750-763 (2004). https://doi.org/10.1109/TMI.2004.826951

34. A.L.M. Silva, C.D.R. Azevedo, C.A.B. Oliveira, J.M.F. Dos Santos, M.L. Carvalho, J.F.C.A. Veloso, Characterization of an energy dispersive X-ray fluorescence imaging system based on a micropattern gaseous detector. Spectrochim. Acta B 66(5), 308-313 (2011). https://doi.org/10.1016/j.sab.2011.03.002

35. A.L. Silva, MPGDs based radiation imaging devices and applications. Phd thesis, Universidade de Aveiro (2013) 